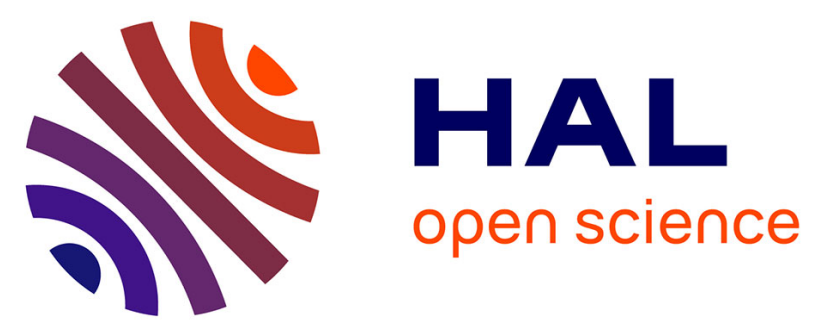

\title{
Contextual Personas as a Method for Understanding Digital Work Environments
}

Åsa Cajander, Marta Larusdottir, Elina Eriksson, Gerolf Nauwerck

\section{To cite this version:}

Åsa Cajander, Marta Larusdottir, Elina Eriksson, Gerolf Nauwerck. Contextual Personas as a Method for Understanding Digital Work Environments. 4th IFIP 13.6 Working Conference on Human Work Interaction Design (HWID), Jun 2015, London, United Kingdom. pp.141-152, 10.1007/978-3-31927048-7_10. hal-01371693

\section{HAL Id: hal-01371693 \\ https://inria.hal.science/hal-01371693}

Submitted on 9 Nov 2016

HAL is a multi-disciplinary open access archive for the deposit and dissemination of scientific research documents, whether they are published or not. The documents may come from teaching and research institutions in France or abroad, or from public or private research centers.
L'archive ouverte pluridisciplinaire HAL, est destinée au dépôt et à la diffusion de documents scientifiques de niveau recherche, publiés ou non, émanant des établissements d'enseignement et de recherche français ou étrangers, des laboratoires publics ou privés.

\section{(c)(1)}

Distributed under a Creative Commons Attribution| 4.0 International License 


\title{
Contextual Personas as a Method for Understanding Digital Work Environments
}

\author{
Åsa Cajander ${ }^{1}$, Marta Larusdottir ${ }^{2}$, Elina Eriksson ${ }^{3}$ and Gerolf Nauwerck ${ }^{1}$ \\ ${ }^{1}$ Uppsala University, Box 337, SE-751 05 Uppsala \\ ${ }^{2}$ Reykjavik University, Menntavegur 1, 101 Reykjavik, Iceland \\ ${ }^{1}$ KTH - Royal Institute of Technology, Lindstedsvägen 3, 10044 Stockholm \\ asa.cajander@it.uu.se, marta@ru.is, elina@kth.se, \\ gerolf.nauweck@uadm.uu.se
}

\begin{abstract}
The role of IT at the workplace has changed dramatically from being a tool within the work environment to include all aspects of social and private life. New workplaces emerge where IT becomes more and more divergent, embedded and pervasive. These new aspects of IT at work need to be addressed with new or adapted human centred activities. This paper present and discuss a modified version of personas called contextual personas developed to better address the new working life. The contextual personas were developed using contextual inquiry, and focus groups as well as argumentative design. From the process of developing the contextual personas we learned that they are indeed a promising tool to understand the new work situations, and especially the holistic view of IT at work as they bring the whole working-life of the personas into focus. Finally, we discuss in what way the contextual personas could give developers extended understanding of the users' future office work environment.
\end{abstract}

Keywords: Personas, digital work environment, usability.

\section{Introduction}

Working life has been changing for many with a move towards goal oriented tasks, informal communication and virtual collaboration. Moreover, the use of IT has moved from being an isolated tool within the work environment to becoming pervasive through for example mobile apps and social media. Hence this shift has led to work that blurs the borders to social and private life, which is related to definition of one's identity as a digital person in a technical world. Often these changes of working life are enhanced through technology with the technical solutions available. It is common that people use various computer systems, including various equipment to use those such as mobile phones, tablets and laptops. Moreover, they are at different places while using the software systems. This creates complexities that are new and challenging. Other new ways of managing private life and working life has emerged, and 
one can note trends like for example BYOD (Bring Your Own Device) where the company policy allows employees to bring their own technology to the workplace. This shift makes systems development ever more complicated and there is an increasing need for illustrating this new work situation in order to better understand all the variations in the work environment that has emerged.

In this study we made extensive contextual interviews with administrative staff at university offices to gather information on their current work situation from a computer supported work environment perspective. In the paper, we explain a new method for describing results of such contextual interviews called contextual personas. These personas are developed to explain the various work contexts of the workers. Our results show that the employees are willing to give rich information about their work context, when prompted through the persona descriptions. Through the focus group discussions of the contextual personas real life was brought into the conversation.

In this paper we describe how contextual personas can be used to elicit IT based administrative work as one method to understand the digital work environment. Firstly the personas can be used as a tool to describe the work situation and the users within this work situation, which also extends to social life. However, we also argue that the contextual personas can be used as a reflexive tool that lets the respondents further reflect on their own work situation. Hence in our study, the contextual personas gave us information on the work environment and potential health hazards when looking at the holistic work situation including IT based tools and the overarching workload. On concrete finding from our interviews has implications for pervasive and smart workplaces, since the perceived connectedness of these administrators led to an always on status which made it hard for them to feel that they were ever free from work. Furthermore we discuss how the personas can be used in pervasive and smart workplaces such as future office spaces presented below.

\section{Background}

When creating the contextual personas, the healthy work model by Karasek and Theorell [1] was used. Hence the first section below presents this model. This is followed by a presentation of future offices and the emerging trends in this area. Finally, we present a short description of research on the personas method.

\subsection{Digital Work Environment and Healthy Work}

As work has become more digitalised the digital work environment becomes more central for employees productivity and also wellbeing. The digital work environment is here defined broadly as the work environment that is the result of digital tools and work support systems. The digital work environment consists of physical, psychosocial and cognitive problems and challenges. It encompasses all cognitive work situations where people interact or are dependent on computer systems. In this definition of the digital work environment we also include aspects of integrity, control and surveillance. 
When analysing the data from the contextual interviews, the Demand-ControlSupport model is used. In the 1970's Robert Karasek developed a model for analysing work-related stressors associated with cardiovascular illness. His demand and control model was thereafter further developed together with Töres Theorell [1] and is now one of the most widely used models for explaining psycho-social work conditions and their effects on health. This model suggests that the combination of perceived demands and perceived control at work is a determining factor for stress. This model was used since our previous research, see for example [2] and [3] that have shown that the model is easily understood and applied in organisations when the digital work environment has been discusses. The figure below illustrates the Demand-ControlSupport Model.

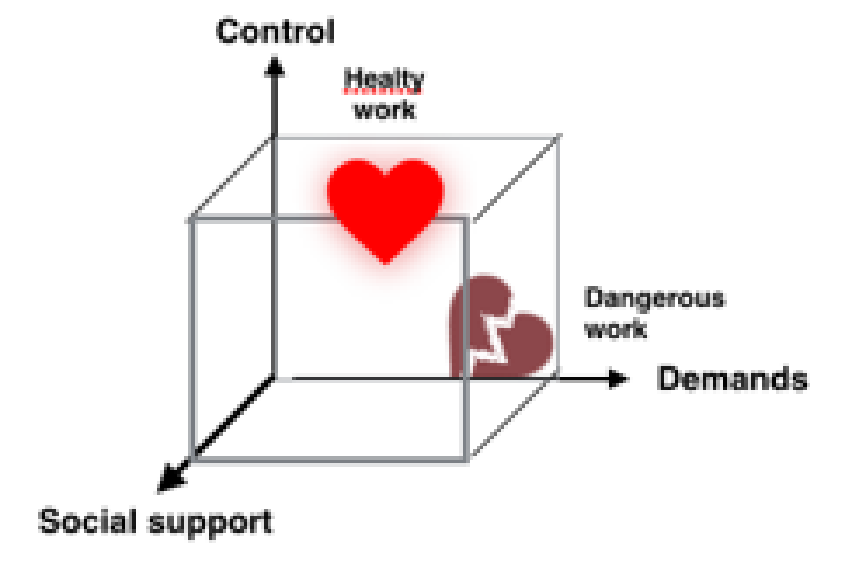

Fig. 1. The Demand-Control-Support Model of stress in a work situation. High job strain, i.e. high demands in combination with low decision latitude, and low social support are associated with the highest risks for health problems.

The figure above illustrates how healthy and sustainable a work is, in relation to the experienced demands, control and social support. High demands are normally not a problem, if combined with high self-control over work situation and tools and strong social support from management and colleagues. A skilled worker can experience this as a challenging situation. She has full control over the work conditions and planning and gets full support when needed. The work is efficient and sustainable. On the other hand, if high demands are not met by strong self-control and social support, the situation will soon become dangerous health wise. If the worker does not have control over work conditions and planning, does not have usable tools and feels totally exposed if things go wrong, the work will be very unhealthy. Such work situations are associated with high stress. In this extreme, different health risks are common and people do not withstand the situation for long. Research shows that subjective control 
and support factors often decrease when new IT systems are introduced, as did Åborg, $[4,5]$.

In this research project we have focused on administrative work. The main health problems in such computer-supported work situations are: Users are bound to use the computer for a major part of their working hours entailing constrained, static work postures for long periods. The computer controls the work pace and task order, leaving the users little or no control over their work. Users suffer from stress, caused by excessive workload, time pressure and poorly designed computer support [6, 7].

Traditionally, occupational health experts work in isolation from the software development process. They evaluate and suggest improvements to existing workplaces and tools [3]. It is, however, often too late to do something about poorly designed software tools once they have been installed and are running. Thus, poor and inadequate design leading to health problems cannot be sufficiently modified post-hoc of systems development when the computer system is in use. Instead, occupational health and ergonomics experts must be involved in the actual software development process. Work-related stress has increased in the past years and since long it is well known that it is a growing health problem [8]. Organisation of work organisation and work content are important factors underlying stress problems, and in work, IT support systems, especially computer software, play a major role. The mental workload tends to increase when new IT systems are introduced [9], and the decision latitude is lower for extensive computer users than for others [10].

\subsection{Future Offices and its Relevance to $\mathrm{HCI}$}

The physical work environment in all its variety is of course another factor influencing office workers [11]. Recently, flexible offices and more specifically management philosophies such as the idea of activity-based working (ABW) has attracted the interest of both organisations and researchers [12]. Place is here seen as a mediating factor between people and IT. Indeed, the strategic use of corporate space is seen as the necessary, though not sufficient, factor in empowering the workforce and ameliorating many of the downsides of computer-supported work [13]. A part of the concept is increased use of IT in support of both mobility and monitoring, and not surprisingly, the IT industry itself is one of the major proponents of this new way of work [14]. Yet, while $\mathrm{ABW}$ is proposed as a solution to the problems associated with open plan offices, not least cognitive stress, research is inconclusive [15]. In a seminal paper [16] traces the origins of this seemingly new-anywhere, anyplace-work rhetoric and exposes some its inherent paradoxes, not least how these images of newness contribute to the conservation of old work patterns.

As IT in the workplace thus becomes more and more embedded and pervasive the scope for HCI broadens. The pioneering works of [17] have already argued for the application of usability concepts in the field of facility management, yet the field seems to have attracted limited attention so far [18]. Instead, the most common tool seems to be variations on the model developed by [19]), where the amount of face-to- 
face interaction is contrasted with the amount of job autonomy (resulting in a matrix of four basic office types: the hive, the cell, the den and the club). While this broad categorisation of work can aid planning, other techniques, such as personas, could provide a deeper understanding on how to improve the quality of work and the work environment.

\subsection{Personas}

Within development of IT-based systems, the persona method has become frequently applied tool and is used extensively in both industry and in research. The persona method is a user-centred way of representing users in situations where users cannot be available; the idea is that the overall focus and awareness of the users in development projects are heightened when working with personas [20]. However the use of the method can be manifold for example, the personas are described both as a communication tool and as a design aid. However, [21] argues that by trying to separate the different ways to use the method will help the usability practitioner to more skillfully use the personas, as well as being open for alternative applications.

Within the field of Human-Computer Interaction, the persona method was originally introduced by Cooper [22], and he argued for hypothetical archetypes of real users in order to avoid designing systems that become too generic and in the end does not fit anyone. According to Cooper [22], the personas should be based on actual users and the personas should be precise and specific since it is more difficult to ignore a detailed persona than aggregated user data. The ideas is that numerous personas initially are created through an iterative process, and then these are condensed, according to their goals, into fewer but more precise, personas. One more important claim from Cooper is that even though multiple personas can be created, the developers should focus on one primary persona [22].

The extensive use of personas result in different views on what should be the basis of the personas. The most common argument is for collecting qualitative data through for example interviews and observations of real users [21, 22, 23]. However, the data underpinning the personas does not need to be based on ethnographic studies of real users; for example [24] describe personas within secure systems design based on assumptions. Quantitative data from for example surveys can also be used to statistically render personas, although these can later be refined by interviews and observations [25]. Moreover, the widespread usage of the method in disparate settings and contexts has made the resulting personas in different shapes and forms. [26] outline in their paper a loose typology of personas, however, the persona kinds that are described in their paper are not exhaustive; for example, other possibilities are assumption personas [24] or a collaboration persona [25]. The persona method is also criticised, where the most alarming critique is that the personas are being misused and that this leads to designers distancing themselves from real users [28]. [28] argues that it is better to engage with users directly than to create a façade of user-centeredness [28]. Other types of critique are that the method is difficult to verify as (more) beneficial compared to other method [29] or that it is inevitable that designers will create stereotypes [30]. Furthermore there is literature that shows when personas have failed to 
work, such as the case that [31] present. The reasons for this was mainly because the design team was not familiar enough with the method and the interaction designers were not involved in the creation of the personas. [32] present a case where the persona method was abandoned in the context of developing software for mass-market mobile devices, although this mainly was because of the power and dominion of stakeholders outside the development organisation. Some recent studies have shown that the probability of personas being used is higher if the designer has participated in the creation of them [27, 33] (. Furthermore, [34] presents a case where personas were used outside the development project in which they were developed. In their case the educational department adopted the personas as a way to introduce newly employed to different clusters of customers.

\section{Using Contextual Personas to Define Current Work Situation}

In this section the background of the study is presented as well as the data gathering method used.

\subsection{The Case Uppsala University}

Uppsala University is a large Scandinavian research university with about 40000 students and 6000 employees. The business administration department of the university handles the overall strategic economy at the university, whereas the different business administrators at the departments work with the daily economical work.

The majority of the business administrators at the departments are women. The work of the business administrators at the different departments at the university are however organised in many different ways. Some work both with economy, human resource matters and study administration since they belong to very small departments, whereas others are very specialized in one area such as EU project economy and work with that full time with the support of a larger group of business administrators. Today, computers constitute the primary working tool for the business administrators at the universities, and hence comprise a major part of the work environment and procedures.

The study presented in this paper was a part of a collaborative project (KiA) between a research group of Human-Computer Interaction and the university administration [35]. The KiA project ran for two years, 2012-2013, and was coordinated by the university administration whereas the researchers did most intellectual contributions. It should be noted that the project was not a research project as such but the researchers were allowed to use the findings for scientific work beyond the project. The researchers worked within a participatory action research tradition $[36,37]$ meaning that they were used to work closely with organisations, rather than observing without interfering. 


\subsection{Data Gathering}

\subsubsection{Contextual Inquiry}

The data gathering was conducted from May to late August 2013. Field studies and interviews were conducted with 12 economics administrators at four different institutions in Uppsala University lasted approximately 2-3 hours. The field studies followed the method Contextual Inquiry and its four principles [38]:

Studies of the work in its context. Field studies were conducted on site. Researchers are studying the users who do their tasks and discuss the systems used to solve them.

Cooperation. The user and researcher work together to understand the user's work. The researcher alternate between observing the user when they work and discuss what the user was doing and why.

Interpretation. The researcher share their interpretations and insights with the user during the interview. The user can expand or correct the researcher's understanding.

Focus. The researcher focus the conversation on topics that are relevant to the survey.

During the field studies the researcher took notes using pen and paper. The first field studies were made with an open mind to understand the work and the situation, but eventually the researcher asked the business administrator more specific questions as for example to show some particular parts of the systems or tasks.

\subsubsection{Data Analysis and Sketches of Contextual Personas}

The collected data was analyzed based on four categories from Karasek and Theorell's model of work [1], and the fourth category was the general working environment problems. Three researchers (three of the authors), analysed the data together in a workshop in August 2013 and wrote the first descriptions of the three personas together during the workshop which resulted in rough contextual personas. The researchers worked visually with the personas and made use of large white boards where the dimensions of healthy work were visualised together with descriptions of personas. After the workshop, the descriptions were reviewed individually by the researchers and modified. The illustrations of the personas were just modified images from Clip Art at this point.

\subsubsection{Focus Groups}

One researcher revisited two of the business administration departments, and arranged focus groups with four and three business administrators to discuss and reflect upon the presentations made in the personas. After the focus groups the personas were revised according to the reflections made by the business administrators. An illustra- 
tor was asked to draw the faces of each persona according to the descriptions at this point.

\section{$4 \quad$ Results}

\subsection{Three Contextual Personas}

Three personas were made based on the interviews and analysis of those. Each description was about one page of text describing the personal life, one day at work and the goals of the persona. Additionally, the need for control, support and the demands that the persona has are described. Each persona had a figure, illustrated by a professional illustrator. One example of a persona can be seen in figure 2 .

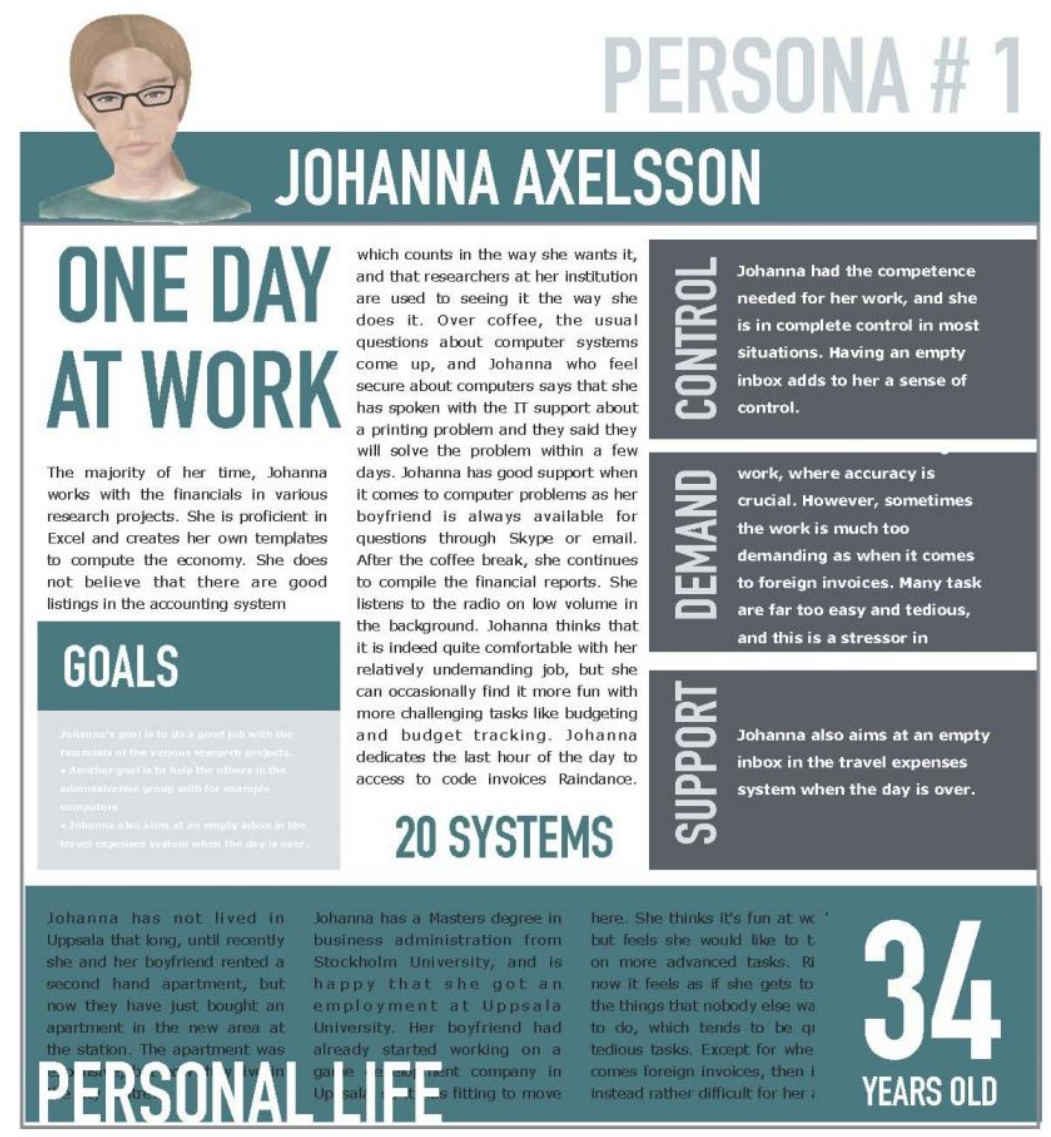

Fig. 2. An example of a persona that was created using the contextual personas method 


\subsection{Reflections on the Contextual Personas}

Some really interesting points emerged during the focus group discussions that did not occur in the earlier interviews. The business administrators really liked the job descriptions made, and could identify themselves with the personas. Someone said, "It really feels like this person is working here".

One of the things that one of the groups wanted to add was how life was affected by their work. In their mind private life and work forms one whole, and they wanted that to be better represented in the personas. They also gave concrete examples of situations where they need to adapt their working hours, their vacation and their weekends to meet the goals of different business administration deadlines. As a business administrator at the university in their opinion, you need to adapt life to work, and they often worked long hours before deadlines. One person described that new deadlines might occur in the calendar if researchers receive new research projects, and that these have individual deadlines for reporting. Especially EU projects mean a lot of work for the business administrators, who adapt their working hours according to the schedule of the projects.

Some business administrators also complained about the current systems at the university that does not support flexible work, and some systems require that you are on the university network to be able to work. They also wanted more possibilities to work using their mobile devices.

Another interesting discussion that emerged was the lack of a persona that would represent the elderly generation of business administrators. This persona would describe the situation that technology has changed work so much that it is not the same at all. The persona would illustrate an elderly lady who has had problems understanding the new technology, and being terrified with the changes even though they are at the very core of their work. This persona has the feeling that her knowledge is not valid any more.

\section{Discussion}

The contextual personas were based on the theory of healthy work by Karasek and Theorell [1]. The theory was used in a very concrete way when designing the personas, and each aspect (control, support, demand) were discussed separately to ensure the quality of the descriptions. However, during the discussions it became clear that some aspect of the workplaces were not fully covered by the theory such as for example the aspect of interruptions and doing things in parallel. Other aspects that are not covered by the model that emerged in the discussions were the personality of the persona and how that affects the perceived stress. The contextual personas method could hence be further improved in the future to cover all aspects of working life through an conceptual development of the theoretical foundations of the process. One possible theoretical model that could be relevant to use to enhance the personas is the EffortReward Imbalance theory that was developed by Johannes Siegrist [39]. This model is widely used in work environment research and would add aspects of intrinsic and 
extrinsic motivation, and overcommitment which is highly relevant in the context of new ways working.

In our contextual personas we describe the holistic work environment as it is today for the business administrators. The main difference in our way of describing personas compared to how Cooper defined personas [22] is that Coopers personas are used for improving one particular software system. The descriptions of these personas are aimed to describe their way of working solving the goals that the software system being developed will support in solving. Contextual personas are not focused on the usage of one system, they are focused on describing the whole context of work, so contextual personas could typically be using 20 software systems for solving various tasks at work. The usage of personas in new contexts is also argued in [40] where the author elaborates on how the users in the study started to more readily talk about their work situation when confronted with the personas that depicted themselves. This could be interpreted as the personas as a reflexive tool to be used as trigger material when talking with users, which in our cased highlighted the diverse and multifaceted work of the business administrators.

Contextual personas describe the current work situation, similar to Cooper's personas [22] and to Hackos and Redish's [41] scenarios. [41] describe two types of scenarios, "task scenarios" that describe the current situation for a persona and "use scenarios", that describe: "the future use of a computer system". Contextual personas could also be used in a similar way, using the contextual personas to give insights into future work environments. Previous research has show that user feedback is often informal and limited [41]. The contextual personas could work as a new human centred activity that would improve the quality of usability work for developers. In that case, the personas should be based on data from brainstorming sessions with users, so the descriptions will not be too hypothetical and superficial. [22] and [38] have emphasised that personas are grounded in interview data from users and are not based on designers imagination.

There is a need to develop and adapt current human centred activities to better address the future workplaces, and contextual personas shows promising results in this context. One should note that contextual personas are not recommended to be used in isolation, but together with other human centred activities to fully incorporate the essence of future work places. We conclude that the personas need to be complemented with a vision work concerning the future needs and visions of the users as well as other user centred activities

\section{Acknowledgments}

This study was made with financial support from Uppsala University Administration through the KiA project (Quality in Use). We would like to thank everyone that participated in the interview study, and those who have given valuable input to this paper. We would also like to thank the illustrator, Maria Osk Jonsdottir, for her professional work on illustrating the faces of the personas. 


\section{References}

1. Karasek, R. and T. Theorell (1992). Healthy Work. Stress, Productivity and the Reconstruction of Working Life. New York, USA, Basic Books.

2. Cajander, Åsa. "Usability-Who Cares?: The Introduction of User-Centred Systems Design in Organisations." (2010).

3. Sandblad, B., Gulliksen, J., Åborg, C., Boivie, I., Persson, J., Göransson, B., et al. (2003). Work environment and computer systems development. Behaviour and Information Technology, 22(6), 375-387

4. Åborg, C. (2002). How does IT feel@ work? And how to make IT better: Computer use, stress and health in office work.

5. Åborg, C., Sandblad, B., Gulliksen, J., \& Lif, M. (2003). Integrating work environment considerations into usability evaluation methods-the ADA approach. Interacting with Computers, 15(3), 453-471.

6. Bergqvist, U. (1995). Visual display terminal work - a perspective on long-term changes and discomforts. International Journal of Industrial Ergonomics, 16(3), 201-209.

7. Punnett, L., \& Bergqvist, U. (1997). Visual display unit work and upper extremity musculoskeletal disordersErgonomic expert committee document/National institute for working life (Solna) (p. 16). Solna.

8. Marklund, S., \& Arbetsmiljöverket, S. (2001). Worklife and health in Sweden 2000. Arbetslivsinstitutet.

9. Aronsson, G. (1989). Dimensions of control as related to work organization, stress, and health. International journal of health services, 19(3), 459-468.

10. Tornqvist, E. W., Eriksson, N., \& Bergqvist, U. (2000). Risks factors at computer and office workplaces. Worklife and Health in Sweden 2000, 189.

11. Bodin Danielsson, C. (2010). The Office-an explorative study. Architectural design's impact on health, job satisfaction and well-being. (Doctoral thesis), KTH Royal Institute of Technology, Stockholm. Retrieved from http://urn.kb.se/resolve?urn:nbn:se:kth:diva24429

12. Appel-Meulenbroek, R., Groenen, P., \& Janssen, I. (2011). An end-user's perspective on activity-based office concepts. Journal of Corporate Real Estate, 13(2), 122-135. doi:10.1108/14630011111136830

13. van Koetsveld, R., \& Kamperman, L. (2011). How flexible workplace strategies can be made successful at the operational level. Journal of Corporate Real Estate, 1(4), 303-319.

14. Gates, B. (2005). The New World of Work. Retrieved October 17, 2014, from https://www.microsoft.com/mscorp/execmail/2005/05-19newworldofwork.mspx

15. Too, L., \& Harvey, M. (2012). "TOXIC" workplaces: the negative interface between the physical and social environments. Journal of Corporate Real Estate, 14(3), 171-181. doi:10.1108/14630011211285834

16. Humphry, J. (2014). Visualising the future of work: myth, media and mobilities. Media, Culture \& Society, 36(3), 351-366. doi:10.1177/0163443713517730

17. Alexander, K. (2006). The application of usability concepts in the built environment. Journal of Facilities Management, 4(4), 262-270. doi:10.1108/14725960610702947

18. Rasila, H., Rothe, P., \& Kerosuo, H. (2010). Dimensions of usability assessment in built environments. Journal of Facilities Management, 8(2), 143-153. doi:10.1108/14725961011041189

19. Laing, A., Duffy, F., \& Jaunzens, D. (1998). New Environments for Working: The ReDesign of Offices and Environmental Systems for New Ways of Working. 
20. Grudin, J., \& Pruitt, J. (2002). Personas, participatory design and product development: An infrastructure for engagement. Paper presented at the PDC'02.

21. Guðjónsdóttir, R. (2010). Personas and Scenarios in Use. (Doctoral thesis Trita-CSC-A), $\mathrm{KTH}$, Sweden.

22. Cooper, A. (2004). The inmates are running the asylum. USA: SAMS publishing.

23. Pruitt, J., \& Grudin, J. (2003). Personas: practice and theory. Paper presented at the Designing for user experiences

24. Faily, S., \& Fléchais, I. (2010). The secret lives of assumptions: Developing and refining assumption personas for secure system design. Paper presented at the Human-Centred Software Engineering.

25. Sinha, R. (2003). Persona development for information-rich domains. Paper presented at the $\mathrm{CHI}$ ' 03 extended abstracts on Human factors in computing systems.

26. Floyd, I. R., Jones, M. C., \& Twidale, M. B. (2008). Resolving incommensurable debates: a preliminary identification of persona kinds, attributes, and characteristics. Artifact, 2(1), $12-26$.

27. Matthews, T., Whittaker, S., Moran, T., \& Yuen, S. (2011). Collaboration personas: A new approach to designing workplace collaboration tools. Paper presented at the CHI 2011.

28. Portigal, S. (2008). Persona non grata. interactions, 15(1), 72-73.

29. Chapman, C. N., \& Milham, R. P. (2006). The personas' new clothes: methodological and practical arguments against a popular method. Paper presented at the The Human Factors and Ergonomics Society Annual Meeting.

30. Turner, P., \& Turner, S. (2011). Is stereotyping inevitable when designing with personas? Design Studies, 32(1), 30-44.

31. Blomquist, A., \& Arvola, M. (2002). Personas in action: ethnography in an interaction design team. Paper presented at the NordiCHI'02.

32. Rönkkö, K., Hellman, M., Kilander, B., \& Dittrich, Y. (2004). Personas is not applicable: local remedies interpreted in a wider context. Paper presented at the Participatory Design Conference.

33. Friess, E. (2012). Personas and decision making in the design process: an ethnographic case study. Paper presented at the CHI 2012, Austin, Texas, USA.

34. Markensten, E., \& Artman, H. (2004). Procuring a usable system using unemployed personas. Paper presented at the Third Nordic Conference on Human-Computer Interaction, Tampere, Finland.

35. Cajander, $\AA$., Nauwerck, G., \& Lind, T. (2015). Things take time: Establishing usability work in a university context. In EUNIS Journal of Higher Education IT (Vol. 2, No. 1).

36. Heron, J., \& Reason, P. (2006). The practice of co-operative inquiry: Research 'with'rather than 'on'people. Handbook of action research, 144-154.

37. McKay, J. and P. Marshall 2001McKay, J., \& Marshall, P. (2001). The dual imperatives of action research. Information Technology \& People, 14(1), 46-59.

38. Holtzblatt, K., Wendell, J. B., \& Wood, S. (2004). Rapid contextual design: a how-to guide to key techniques for user-centered design. Elsevier.

39. Siegrist, J., Starke, D., Chandola, T., Godin, I., Marmot, M., Niedhammer, I., et al. (2004). The measurement of effort-reward imbalance at work: European comparisons. Social science \& medicine, 58(8), 1483-1499.

40. Eriksson, E. (2013). Situated Reflexive Change : User-Centred Design in(to) Practice. (Doctoral thesis), KTH Royal Institute of Technology, Stockholm. Retrieved from http://urn.kb.se/resolve?urn=urn:nbn:se:kth:diva-116403

41. Hackos, J. T., \& Redish, J. (1998). User and task analysis for interface design, New York: John Wiley \&, Sons. 
42. Larusdottir, M. K., Cajander, A, Gulliksen, J (2014): Informal Feedback Rather Than Performance Measurements - User Centred Evaluation in Scrum Projects. Behaviour and Information Technology. Vol 33 - issue 11, pg. 1118 - 1135. DOI: 10.1080/0144929X.2013.857430. 